\title{
Physicochemical characterization of starch extracted from Malaysian wild yam (Dioscorea hispida Dennst.)
}

\author{
Airul Ashri ${ }^{1}$, M. Sukeri M. Yusof ${ }^{2}$, M. Suzeren Jamil ${ }^{1}$, Aminah Abdullah ${ }^{1}$, S. Fairus M. Yusoff ${ }^{1}$, M. Nasir M. \\ Arip $^{3}$ and Azwan Mat Lazim ${ }^{*}$

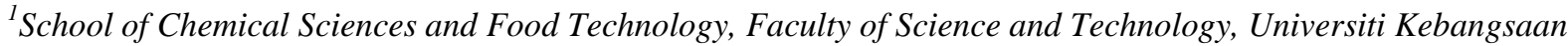 \\ Malaysia 43600 Bangi, Selangor, Malaysia \\ ${ }^{2}$ School of Chemical Sciences, Faculty of Science and Technology, Universiti Malaysia Terengganu, Mengabang Telipot, \\ 21030, Kuala Terengganu, Terengganu Malaysia \\ ${ }^{3}$ Forest Products Division, Forest Research Institute Malaysia 52109 Kepong, Selangor, Malaysia
}

\begin{abstract}
Using a sedimentation method, the extracted starch from Dioscorea hispida tuber was characterized for their morphological, thermal and other physicochemical properties such as total starch content, moisture content, $\mathrm{pH}$, water binding capacity (WBC), solubility and swelling power. The starch content extracted from the tuber was $11.46 \%$ with the WBC and moisture content were $107 \%$ and $249 \%$ respectively. Results showed the starch solubility and swelling power gradually increased with the increasing of temperature ranging from $65^{\circ} \mathrm{C}$ to $95^{\circ} \mathrm{C}$. Under a scanning electron microscope (SEM), it was observed the starch granules have polyhedral shapes and their size between $1.3 \mu \mathrm{m}$ to $4.3 \mu \mathrm{m}$. The results obtained from differential scanning calorimeter (DSC) showed the starch transition temperature (To, Tp and Tc) were $74.54^{\circ} \mathrm{C}, 79.35^{\circ} \mathrm{C}$ and $83.36^{\circ} \mathrm{C}$ whereas, enthalpy of gelatinization ( $\Delta \mathrm{Hgel}$ ) was $4.12 \mathrm{Jg}^{-1}$. This research identify that starch from $D$. hispida has unique properties which can be used as a new starch source for various applications.
\end{abstract}

Key words: Dioscorea hispida, DSC, Physicochemical properties, SEM, Starch

\section{Introduction}

Starch is reported as one of the most versatile macromolecules and also listed as the second largest natural biopolymer next to cellulose. It is hydrophilic in nature, abundant, renewable and fully biodegradable carbohydrate polymer that requires low preparation cost (Wang et al., 2003). Generally, starch has two major components namely amylose and amylopectin. Amylose is in a linear chain, amorphous which linked together by $\alpha-(1,4)$-linked bond whereas amylopectin exist as branched structure with an extra bond of $\alpha-(1,6)$ linked that mostly present as crystalline forms. For a long time starch has been mainly used in food products but today, it also utilized in paper, textiles,

Received 09 September 2013; Revised 23 December 2013; Accepted 12 January 2014; Published Online 15 June 2014

*Corresponding Author

Azwan Mat Lazim

School of Chemical Sciences and Food Technology, Faculty of Science and Technology, Universiti Kebangsaan Malaysia 43600 Bangi, Selangor, Malaysia

Email: azwani79@ukm.my adhesives, beverages, confectionery, plastics including pharmaceutical purposes (Nand et al., 2008, Raheem, 2012).

Dioscorea hispida or locally known in Malaysia as 'ubi gadong' is a starchy tuber which belongs to the genus Dioscorea within Dioscoreaceae family. It is a poisonous creeping plant with a prickly stem twining to the left which can reach up to 20 meters in height, possesses a trifoliate leaves, hairy, form a bulky tuber which having white to yellow flesh and produces a small, pale yellow flower. Their habitat easily grows in the shade or near streams and simply be found in secondary forest (Nashriyah et al., 2010). It is reported easily found in India, Southern China including throughout Southeast Asia to New Guinea (Denham et al., 2007).There are about 1137 species of Dioscorea around the world however only 600 of them are edible (Agbor-egbe and Treche, 1995; Poornima and Rai, 2009; Nashriyah et al., 2010).

Dioscorine, having a molecular formula of $\mathrm{C}_{13} \mathrm{H}_{19} \mathrm{O}_{2} \mathrm{~N}$ is one of the water-soluble alkaloid found in the tuber of $D$. hispida which is extremely 
toxic. Uniquely, this tuber is toxic in nature but it can be turned to be edible after it has been processed in a proper way (Hudzari et al., 2011a; Muhammad et al., 2012). Chemicals such as alkaloid, tannin and saponin may attribute to the toxicity of the tuber. Tannins give an acrid taste whereas saponins cause the bitterness.

Traditionally, the tuber can be detoxified by boiling, roasting or soaking in flowing water for 714 days (Hudzari et al., 2011b). Detoxified $D$. hispida used to be a staple food in the old days for rural area people where they made it into flour, cakes, pancakes and porridge. However today, it has been forgotten because of the difficulties of traditional detoxification process. The safe amount of tuber that can be consumed as set by World Health Organization (WHO) in 1988 is below 10 mg hydrogen cyanide ( $\mathrm{HCN})$ per kg body weight (Mlingi et al., 1995). However if the tuber is consume excessively (without further purification), it may result in cyanide poisoning with the symptoms such as vomiting, nausea, stomach pains, diarrhea and impart serious health complication. For severe cases of alkaloid intoxication it may cause fatal reactions led to death (Andri et al., 2011; Shajeela et al., 2011).

On contrary the drawbacks, D. hispida has many beneficial functions due to their active components, however starch is often neglected and discarded during its isolation. Extensive researches have been conducted on the structure and functional behavior of the variety of Dioscorea species, but there is no attempt made to evaluate the properties of starch from $D$. hispida. Thus, this study was conducted to identify the D. hispida starch properties and also to investigate the possibilities of their further applications.

\section{Materials and Methods \\ Materials}

Dioscorea hispida Dennst was obtained from Kuala Berang, Terengganu, Malaysia.

\section{Extraction of starch}

A method reported by Nand et al. (2008) was used for starch extraction. The fresh tubers (Figure 1a) were washed, peeled, and sliced into small pieces using a grater and pulverized using a kitchen blender (Panasonic MX-900M) for $1 \mathrm{~min}$. The pulp was suspended in adequate amount of distilled water before the slurry stirred for 30 minutes and filtered using cheesecloth. The filtrate was left overnight for the starch to settle. The supernatant was removed and the starch was dried at $40^{\circ} \mathrm{C}$ until it was completely desiccated and finally collected.

\section{Physicochemical properties of starch The starch pH}

In order to determine the $\mathrm{pH}$, method reported by Muazu et al. (2011) was followed. About $1 \mathrm{~g}$ of starch was weighed and properly mixed with $3 \mathrm{~mL}$ of distilled water. Boiling distilled water was poured into the mixture to make up $20 \mathrm{~mL}$ of slurry before it was allowed to cool. The $\mathrm{pH}$ of the starch was determined using a Jenway digital $\mathrm{pH}$ meter model 3505.

\section{Moisture content}

Moisture content was determined by using the oven-dry method (Olayemi et al., 2008) where 100 grams of starch was weighed in a petri dish. Then it was placed in an oven at a temperature of $110^{\circ} \mathrm{C} \pm$ $5^{\circ} \mathrm{C}$. The mass of the starch was weighed in hourly intervals until two constants of mass were obtained. Once the constant mass achieved, the starch was allowed to cool at room temperature before the final mass was recorded. The moisture content was calculated using the formula below:

Moisture content $=\frac{\operatorname{Starch}_{\mathrm{W}}-\mathrm{Starch}_{\mathrm{D}}}{\mathrm{Starch}_{\mathrm{D}}} \times 100$

*Where $\operatorname{Starch}_{\mathrm{W}}$ is weight of wet sample in gram and $\mathrm{Starch}_{\mathrm{D}}$ is weight of dry sample.

\section{Water binding capacity (WBC)}

The water binding capacity of starch was determined by using a method reported by Yamazaki (1953) and Medcalf and Gilles (1965). A gram of starch was dissolved in $15 \mathrm{~mL}$ of distilled water. The mixture was agitated for $1 \mathrm{~h}$ and centrifuged at $3000 \mathrm{rpm}$ for 10 minutes. The supernatant was discarded from the wet starch, drained and weighed.

$$
\% \mathrm{WBC}=\frac{\text { Bound water }}{\text { Weight of sample(dry basis })} \times
$$

\section{Solubility and swelling power of starch}

The solubility and swelling power of starch were determined by heating $1 \%$ aqueous suspension of starch in a water bath at $65^{\circ} \mathrm{C}, 75^{\circ} \mathrm{C}$, $85^{\circ} \mathrm{C}$ and $95^{\circ} \mathrm{C}$ for 30 minutes (Jiang et al., 2012; Riley et al., 2006). Samples were cooled until it reached at room temperature; the suspension was then centrifuged at $3000 \mathrm{rpm}$ for 15 minutes. The supernatant was carefully poured into a petri dish and evaporated overnight at $110^{\circ} \mathrm{C}$ while the swollen sediment was weighed. The analysis was performed in triplicate. The swelling power and solubility were calculated as follows:

Swelling power $(\mathrm{g} / \mathrm{g})=\frac{(\mathrm{SW} \times 100)}{\text { Starch }_{\mathrm{dwwb}}} \times(100 \%-\% \mathrm{SOL})$ 
Solubility $\left(\%\right.$ SOL) $=$ Weight of dried supernatant $\times \frac{100}{\text { Starch }_{\text {dwb }}}$

*SW is the weight of wet sediment and Starch $_{\mathrm{dwb}}$ is the dry water basis starch weight

\section{Thermal analysis (DSC)}

Thermal property of starch was analyzed by using the Perkin-Elmer differential scanning calorimeter (DSC). First, the starch was dissolved with distilled water in an Aluminium pan at a ratio of 1:4. Then the suspension was hermetically sealed and allowed to equilibrate for at least $1 \mathrm{~h}$ at room temperature. Sample was heated at a rate of $10^{\circ} \mathrm{C} / \mathrm{min}$ from $20^{\circ} \mathrm{C}$ to $120^{\circ} \mathrm{C}$ in an empty Aluminium pan which made as a reference.

\section{Morphology analysis (SEM)}

The dried-starch sample was placed on a metal stub with doubled-sided adhesive tape and then coated with gold powder under vacuum to make the sample conductive. The morphology property of starch was observed by using a scanning electron microscope (SEM Philips XL30) and the image was taken at an acceleration potential of $20 \mathrm{kV}$.

\section{Results and Discussion \\ Physicochemical analysis}

The properties of starch isolates from $D$. hispida (Figure 1b) were characterized and also compared with other species of Dioscorea (Table 1). It was found that the D. hispida starch content was about $11.46 \pm 0.08 \%$ which was much lower than that reported by Jiang et al. (2012). Moreover, in comparison with other species, their moisture content and water binding capacity (WBC) were also low with $107 \%$ and $249 \%$ respectively (Table 1). According to Hoover and Ratnayake (2002) this result is possibly due to the starch hydroxyl group that tends to form hydrogen and covalent bonds with starch chains rather than water. This gives an initial idea of $D$. hipida starch structure and its acidic conditions ( $\mathrm{pH}$-approximately $4.48 \pm 0.03$ ).

Table 1. Physicochemical properties of starch from D. hispida and five different Dioscorea species.

\begin{tabular}{|c|c|c|c|c|c|}
\hline \multirow[b]{2}{*}{ Source } & \multirow[b]{2}{*}{ Species } & \multicolumn{4}{|c|}{ Physicochemical properties } \\
\hline & & $\begin{array}{l}\text { Starch content } \\
(\%)\end{array}$ & $\begin{array}{l}\text { Moisture content } \\
(\%)\end{array}$ & WBC (\%) & $\mathrm{pH}$ \\
\hline \multirow[t]{2}{*}{-} & *D. hispida & $11.46 \pm 0.08$ & $2.49 \pm 0.6$ & $1.07 \pm 0.02$ & $4.48 \pm 0.03$ \\
\hline & D. opposita & $69.90 \pm 0.02$ & $13.46 \pm 0.86$ & $1.41 \pm 0.01$ & - \\
\hline \multirow[t]{3}{*}{ Jiang et al. (2012) } & D. alata & $41.90 \pm 0.01$ & $14.35 \pm 0.84$ & $1.56 \pm 0.11$ & - \\
\hline & D. nipponica & $35.40 \pm 0.03$ & $11.62 \pm 0.33$ & $4.43 \pm 0.03$ & - \\
\hline & D. bulbifera & $62.70 \pm 0.01$ & $12.26 \pm 0.50$ & $2.53 \pm 0.02$ & - \\
\hline
\end{tabular}

The results are mean of triplicates determination \pm standard deviation.

*Results obtained in this research.

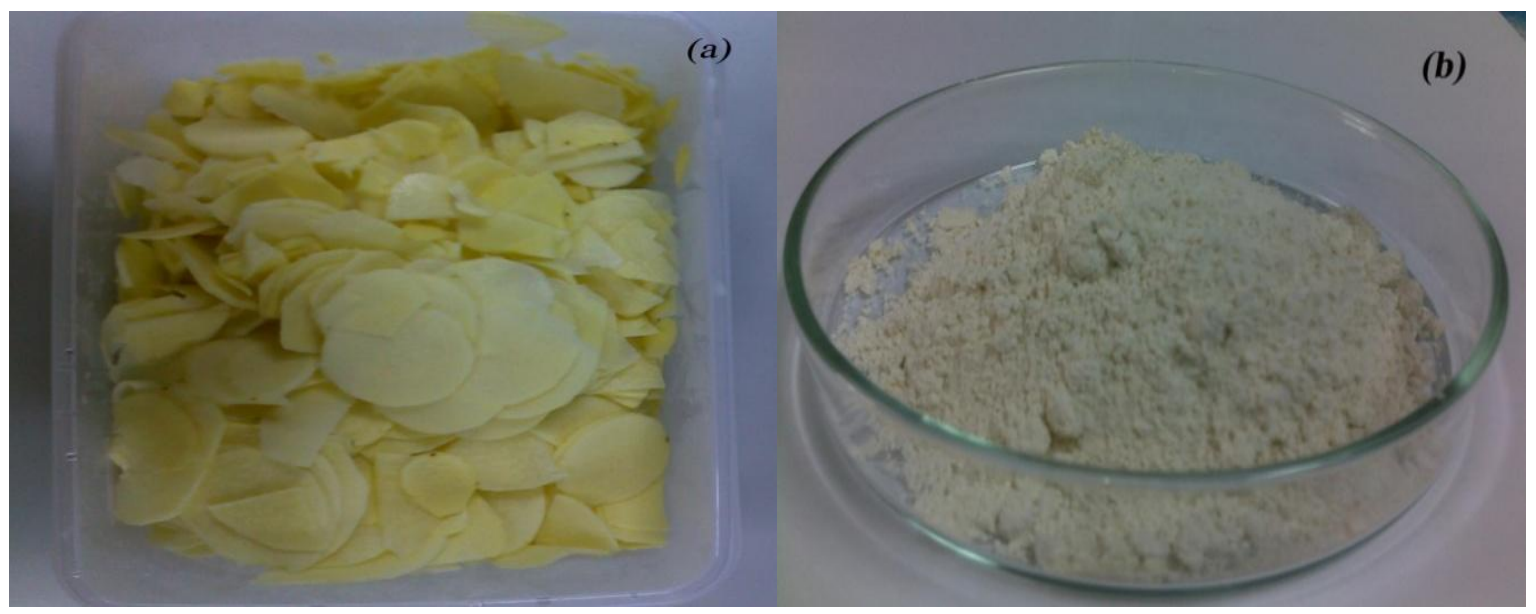

Figure 1. (a) Fresh tuber of D. hispida whereas (b) the starch extracted from D. hispida. 
In order to determine the swelling power and solubility of $D$. hispida isolated starch, the temperature was increased gradually from $65^{\circ} \mathrm{C}$ to $95^{\circ} \mathrm{C}$ for 30 minutes. The weight of the swollen starch was measured and the data was recorded as shown in Figure 2. Upon the temperature increment, the swelling power was steadily rose from 4.8 to 18.25 . The trend was similarly obtained for starch solubility, stepped-up at about $67 \%$ from initially $6.66 \%$ to $20.0 \%$. Both results due to the intermolecular bondings broke hence allowing the hydrogen bonds to bind more with water molecules (Tester and Morrison, 1990; Udachan et al., 2012). According to Takahashi and Seib (1988), at 50 $60^{\circ} \mathrm{C}$ the amylose starch exists as crystals form and therefore inhibit excessive granule to swell (Coulibaly et al., 2013). As the temperature increases above $65^{\circ} \mathrm{C}$, more energy is absorbed and crystallites melt resulting the starch swelled. This explains why the starch swelled faster above $75^{\circ} \mathrm{C}$. Other factors contributed to the swelling power and the solubility included the ratio of amylose and amylopectin, chain length, molecular weight distribution, degree and length of branches including the conformation of starch molecules (Atoubi, 2011; Udachan et al., 2012).

Further investigations were made to determine the gelatinization temperature, such as onset temperature $\left(\mathrm{T}_{\mathrm{o}}\right)$, peak temperature $\left(\mathrm{T}_{\mathrm{p}}\right)$, conclusion temperature $\left(\mathrm{T}_{\mathrm{c}}\right)$ and enthalpy of gelatinization
$\left(\Delta \mathrm{H}_{\text {gel }}\right)$ by using DSC. As shown in Table 2, D. hispida starch showed a high $\mathrm{T}_{\mathrm{o}}$, with $74.54{ }^{\circ} \mathrm{C}$ which suggested that more energy was required to initiate the gelatinization (Table 2). The result was in agreement with other species where starch from D. septemloba gave the highest $\mathrm{T}_{\mathrm{o}}\left(75.4{ }^{\circ} \mathrm{C}\right)$ followed by D. opposita (D.47) starch $\left(75.06{ }^{\circ} \mathrm{C}\right)$ as reported in Table 2. However, a research carried out by Jiang et al. (2012) on the $\mathrm{T}_{\mathrm{o}}$ of D. opposita starch was not consistent with the result discovered by Shujun et al. (2006), where they obtained the lowest $\mathrm{T}_{\mathrm{o}}\left(68.1{ }^{\circ} \mathrm{C}\right)$ among of all species. For $\mathrm{T}_{\mathrm{p}}$ and $\mathrm{T}_{\mathrm{c}}$ starch extracted from $D$. hispida were also in ranged as reported for Dioscorea species, between $74.33-81.5^{\circ} \mathrm{C} \quad\left(\mathrm{T}_{\mathrm{p}}\right)$ while $77.05 \quad-92.03^{\circ} \mathrm{C} \quad\left(\mathrm{T}_{\mathrm{c}}\right)$ respectively. However in comparison with other Dioscorea species, $\Delta \mathrm{H}_{\mathrm{gel}}$ value for $D$. hispida was $4.12 \mathrm{Jg}^{-1}$ which considered low.

It was also observed that, the differences in gelatinization temperature attributed by amylose content, size, shape, distribution and water binding capacity of starch granule as well as their internal arrangement (Jiang et al., 2012). The results discussed above were also supported by the percentage of WBC. As suggested by Wang et al. (2006) the proportion of hydroxyl group in forming hydrogen and covalent bonding between starch chains was higher compared to water molecular resulting in low WBC. This condition has increased the gelatinization temperature.
Swelling power $(\mathrm{g} / \mathrm{g})$

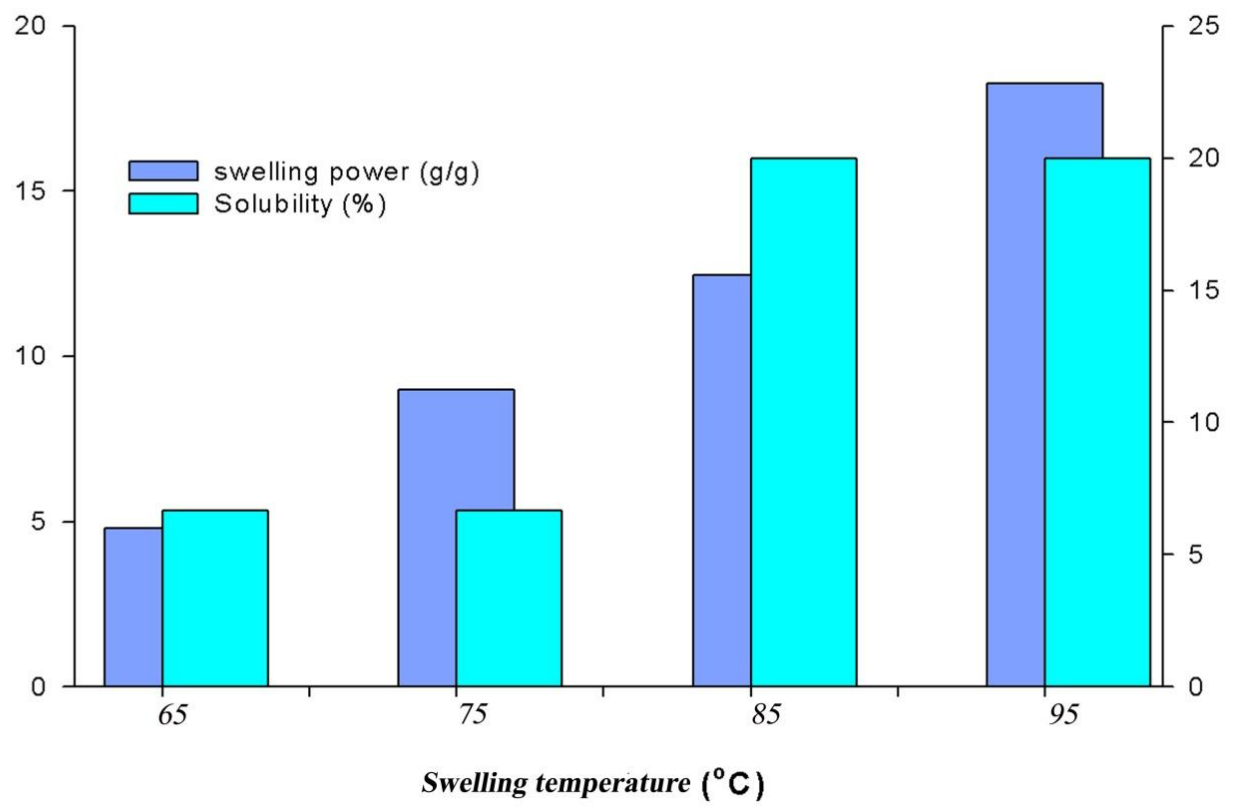

Figure 2. Swelling power and solubility of starch from Dioscorea hispida.

Solubility (\%)

25 
Table 2. Gelatinization temperature of Dioscorea species.

\begin{tabular}{|c|c|c|c|c|c|}
\hline Sources & Species & $\mathrm{T}_{\mathrm{o}}\left({ }^{\circ} \mathrm{C}\right)$ & $\mathrm{T}_{\mathrm{p}}\left({ }^{\mathrm{o}} \mathrm{C}\right)$ & $\mathrm{T}_{\mathrm{c}}\left({ }^{\circ} \mathrm{C}\right)$ & $\mathrm{H}_{\mathrm{gel}}(\mathrm{J} / \mathrm{g})$ \\
\hline \multirow[t]{5}{*}{ Jiang et al. (2012) } & D. opposita & 68.10 & 79.76 & 92.03 & 3.00 \\
\hline & D. alata & 71.26 & 74.33 & 82.11 & 3.58 \\
\hline & D. nipponica & 70.09 & 77.63 & 85.18 & 0.64 \\
\hline & D. bulbifera & 71.63 & 75.98 & 81.23 & 2.05 \\
\hline & D. septemloba & 75.06 & 80.74 & 84.74 & 0.28 \\
\hline \multirow[t]{4}{*}{ Shujun et al. (2006a) } & D. opposita (Baiyu) & 74.0 & 78.8 & 83.3 & 8.41 \\
\hline & D. opposita (Jichengerhao) & 73.6 & 79.4 & 85.0 & 12.40 \\
\hline & $\begin{array}{l}\text { D. opposita } \\
\text { (Jiaxiangxichangmao) }\end{array}$ & 74.8 & 81.0 & 85.7 & 11.78 \\
\hline & $\begin{array}{l}\text { D. opposita } \\
\text { (Jinchengyihao) }\end{array}$ & 74.2 & 80.7 & 87.2 & 11.16 \\
\hline \multirow[t]{2}{*}{ Shujun et al. (2006b) } & D. opposita ( D.47) & 75.4 & 80.9 & 85.5 & 11.37 \\
\hline & D. opposita (SXY) & 74.2 & 81.5 & 86.6 & 10.78 \\
\hline \multirow[t]{8}{*}{ Riley et al. (2006) } & D. alata (Sweet yam) & 73.01 & 75.40 & 79.01 & 4.80 \\
\hline & D. alata (White yam) & 72.09 & 74.32 & 77.05 & 11.31 \\
\hline & D. alata (Renta yam) & 72.93 & 76.93 & 79.12 & 6.72 \\
\hline & D. alata (Moonshine) & 73.20 & 75.71 & 80.23 & 12.75 \\
\hline & D. alata (Darknight) & 73.36 & 75.69 & 79.50 & 6.11 \\
\hline & D. alata (Barbados) & 72.85 & 76.90 & 79.32 & 7.10 \\
\hline & D. alata (Purple/white) & 74.18 & 76.49 & 79.51 & 8.45 \\
\hline & D. alata (Calabash) & 71.36 & 74.43 & 78.87 & 11.51 \\
\hline- & *D. hispida & 74.54 & 79.35 & 83.36 & 4.12 \\
\hline
\end{tabular}

*Results obtained in this research
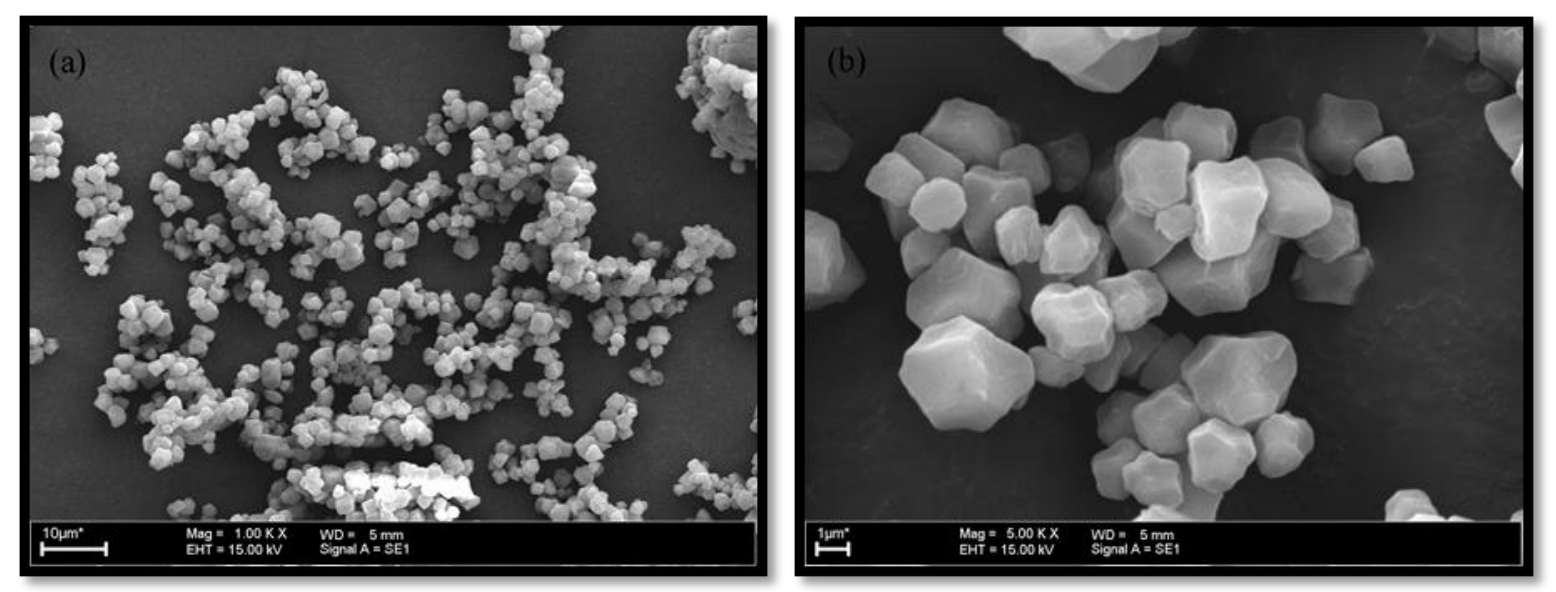

Figure 3. SEM micrographs of Polyhedral shape of starch from D.hispida at (a) 1000x and (b) 5000x.

Figure 3 showed SEM micrographs of polyhedral shape obtained from the starch granule isolated from $D$. hispida with sizes ranging from $1.3 \mu \mathrm{m}$ to $4.3 \mu \mathrm{m}$. The shape was uniquely different from other Dioscorea species owing to the differences in biological origin and growing environment (Svegmark and Hermansson, 1993). A comparison has made with previously reported shapes (Table 3). As example Riley et al. (2006) reported that starch from $D$. alata can have three different forms ie., ellipsoid, polyhedral, triangular or rod-like shape. In the same year, Shujun et al. (2006) claimed that they observed three irregular shapes of D. opposita starch; oval, cake-shaped and ground granules. In their latest study Jiang et al. (2012) proposed that the Dioscorea species played a vital role in producing the final shapes of that particular starch (Table 3). On the other hand it also depends on the biochemistry of the chloroplast, amyloplast including the physiology of the plant. Physical properties such as light transmittance, total amylose content, swelling power and water binding capacity amongst of the factors that affected the average granule size (Kaur et al., 2002; Singh and Singh, 2001; Zhou et al., 1998). 
Table 3. Granule shape of Dioscorea species.

\begin{tabular}{llll}
\hline Sources & Species & Yam cultivars & Granule shape \\
\hline Jiang et al. (2012) & D. opposita & - & Spherical or oval \\
& D. alata & - & Spherical or oval \\
& D. nipponica & - & Lenticular-shaped \\
& D. bulbifera & - & Irregular or polygonal flat \\
& D. septemloba & - & Oval or elongated \\
Shujun et al. (2006a) & D. opposita & Jichengerhao & Oval or ellipsoid \\
& & Jiangxiangxichangmao & Oval or cake-shaped \\
& & Jinchengyihao & Oval or cake-shaped \\
& & Baiyu & Oval or cake-shaped \\
Shujun et al. (2006b) & D. opposita & D.47 & Round or oval to irregular \\
& & D.SXY & Round or oval to irregular \\
Riley et al. (2006) & D. alata & Sweet yam & Ellipsoid \\
& & White yam & Polyhedral \\
& Renta yam & Triangular, ellipsoid \\
& & Moonshine & Ellipsoid \\
& & Darknight & Ellipsoid \\
& & Barbados & Triangular, ellipsoid \\
& & Purple/white & Ellipsoid, rod-like \\
\hline
\end{tabular}

\section{Conclusions}

The results of physicochemical, thermal and morphological properties of starch isolated from $D$. hispida were characterized and compared with starch from other Dioscorea species. It was found that the swelling power and solubility of D. hispida starch was directly proportional to the treatment temperature. The SEM results showed D. hispida has polyhedral morphological shape with small granule size in ranged of $1.3 \mu \mathrm{m}$ to $4.3 \mu \mathrm{m}$. Hence this also contributed to differences of gelatinization temperature parameters which $74.54^{\circ} \mathrm{C}\left(\mathrm{T}_{\mathrm{o}}\right)$, $74.33^{\circ} \mathrm{C}\left(\mathrm{T}_{\mathrm{p}}\right), 77.05^{\circ} \mathrm{C}\left(\mathrm{T}_{\mathrm{c}}\right)$ and their $\Delta \mathrm{H}_{\text {gel }}$ value was $4.12 \mathrm{Jg}^{-1}$ respectively. It is important having all the information on D.hispida starch properties so they can be used as a basic for further applications.

\section{Acknowledgements}

The authors would like to thank the Ministry of Higher Education (MOHE) and Universiti Kebangsaan Malaysia (UKM) for supporting this work by a research grant FRGS/1/2011/SG/ UKM/ $02 / 25$.

\section{References}

Agbor-Egbe, J. and S. Treche. 1995. Evaluation of chemical composition of Cameroonian germplasm. J. Food Comp. Anal. 8:274-283.

Andri, C. K., D. S. Retnowati and C. Budiyati. 2011. Removal of cyanides from Gadung (Dioscorea hispida Dennst.) tuber chips using leaching and steaming techniques. J. Appl. Sci. Res. 7:2140-2146.
Atoubi, C., E. Sakyi-Dawson, S. Sefa-Dedeh, E. O. Afoakwa and A. S. Budu. 2011. Microstructural and physic-functional characterization of starches from selected cowpea (Vigna unguiculata L. Walp.) varieties developed for pest and disease resistance. J. Nutr. Food Sci. 1(2):1-5.

Coulibaly, S., F. A. Tetchi, M. Adou and G. N. Amani. 2013. Comparative characterization of some functional properties of flours of new plantin hybrids with the Orishele variety (Musa spp.) as control. Emir. J. Food Agric. 25:1-9.

Denham, T. J. Iriarte and L. Vrydaghs. 2007. Rethinking agriculture: archaeological and ethnoarchaeological perspective. Left Coast Press, Inc., America pp. 60-70.

Hoover, R. and W. S. Ratnayake. 2002. Starch characteristics of black bean, chick bean, lentil, navy bean and pinto bean cultivars grown in Canada. Food Chem. 78:489-498.

Hudzari, R. M., M. A. H. A. Ssomad, Y. M. Rizuwan, M. N. N. Asimi and A. B. C. Abdullah. 2011a. Development of automatic alkaloid removal system for Dioscorea hispida. Front. Sci. 1:16-20.

Hudzari, R. M., M. A. H. A. Ssomad, Y. M. Rizuwan, M. N. N. Asimi, A. B. C. Abdullah and M. Z. M. Fauzan. 2011b. Modification of automatic alkaloid removal system for dioscorine. Int. J. Agron. Plant. Prod. 2:155-161. 
Jiang, Q., W. Gao, X. Li, Y. Xia, H. Wang, S. Wu, L. Huang, C. Liu and P. Xiao. 2012. Characterizations of starches isolated from five different Dioscorea L. species. Food Hydrocoll. 29: 35-41.

Kaur, L., N. Singh and N. S. Sodhi. 2002. Some properties of potatoes and their starches II. Morphological, thermal rheological properties of starches. Food Chem. 79:183-192.

Medcalf, M. J. and K. A. Gilles. 1965. Wheat starches. I. Comparison of physicochemical properties. Cereal Chem. 42:558-568.

Mlingi, N. L.V., Z. A. Bainbridge, N. H. Poulter and H. Roslin. 1995. Critical stages in cyanogens removal during cassava processing in southern Tanzania. Food Chem. 53:29-33.

Muazu, J., H. Musa, A. B. Isah, P. G. Bhatia and G. M. Tom. 2011. Extraction and characterization of kaffir potato starch: A potential source of pharmaceutical raw material. J. Nat. Prod. Plant Resour. 1:41-49.

Muhammad, A. W., N. Mat and M. H. Razali. 2012. A review on the effect of irrigation in Dioscorea hispida Dennst. growth and phtyochemical. Int. J. Agric. Res. Rev. 2:39-46.

Nand, A. V., R. P. Charan, D. Rohindra and J. R. Khurma. 2008. Isolation and properties of starch from some local cultivars of cassava and taro in Fiji. S. Pac. J. Nar. Sci. 26:45-48.

Nashriyah, M., N. Yusoff, S. Tajuddin, N. Ngah and M. R. M. Rejab. 2010. Dioscorea hispida Dennst (Dioscoreaceae): An overview. Buletin UniSZA, December.

Olayemi, O. J., A. R. Oyi and T. S. Allagh. 2008. Comparative evaluation of maize, rice and wheat starch powders as pharmaceutical excipients. J. Pharm. Sci. 7:131-138.

Poornima, G. N. and V. R. Rai. 2009. Evaluation of phytochemicals and vitamin contents in a wild yam, Dioscorea belophylla (prain) Haine. Afr. J. Biotechnol. 8:971-973.

Raheem, D. 2012. Application of plastics and paper as food packaging materials-An overview. Emir. J. Food Agric. 25:177-188.

Riley, C. K., A. O. Wheatley and H. N. Asemota. 2006. Isolation and characterization of starches from eight $D$. alata cultivars grown in Jamaica. Afr. J. Biotech. 5:1528-1536.
Shajeela, P. S., V. R. Mohan, L. L. Jesudas and P. T. Soris. 2011. Nutritional and antinutritional evaluation of wild yam (Dioscorea spp.). Trop. Subtrop. Agroecosyst. 14:723-730.

Shujun, W., L. Hongyan, G. Wenyuan, C. Haixia, Y. Jiugao and $X$. Peigen. 2006a. Characterization of new starches separated from different Chinese yam (Dioscorea opposita Thunb.) cultivars. Food Chem. 99:30-37.

Shujun, W., Y. Jinglin, G. Wenyuan, L. Hongyan and X. Peigen. 2006b. New starches from traditional Chinese medicine (TCM)-chinese yam (Dioscorea opposita Thunb) cultivars. Carbohyd. Res. 341:289-293.

Singh, J. and N. Singh. 2001. Studies on the morphological, thermal rheological properties of starch separated from some Indian potato cultivars. Food Chem. 75:67-77.

Svegmark, K. and A. M. Hermansson. 1993. Microstructure rheological properties of composites of potato starches granules amylose: A comparison of observed predicted structure. Food Struct. 12:181-193.

Takahashi, S. and P. A. Seib. 1988. Paste and gel properties of prime corn and wheat starches with and without native lipids. Cereal Chem. 65:474-483.

Tester, R. F. and W. R. Morrison. 1990. Swelling and gelatinization of cereal starches I. Effects of amylopectin, amylose and lipids. Cereal Chem. 67:551-557.

Udachan, S., A. K. Iranna and S. G. M. Hend. 2012. Extraction and characterization of Sorghum (Sorghum bicolor L. Moench) starch. Internat. Food Res. J. 19:315-319.

Wang, S. J., W. Y. Gao, H. Y. Liu, H. X. Chen, J. G. Yu and P. G. Xiao. 2006. Studies on the physicochemical, morphology, thermal and crystalline properties of starches separated from different Dioscorea opposita cultivars. Food Chem. 99:38-44.

Yamazaki, W. T. 1953. An alkaline water retention capacity test for the evaluation of cookies baking potentialities of soft winter wheat flours. Cereal Chem. 30:242-246.

Zhou, M., K. Robards, M. Glennie-Holmes and S. Helliwell. 1998. Structure pasting properties of oat starches. Cereal Chem. 75:273-281. 